\title{
Correspondence
}

\section{Mourning by the family after a stillbirth or neonatal death}

\section{Sir,}

In his article (Archives, 1979, 54, 303), Dr Lewis suggested that mourning a stillborn child is facilitated by concentrating on the dead baby, and that an identity is created for the baby by the parents seeing and holding him, talking to the staff, and having a funeral and known burial place for him. Dr Lewis makes little of the more important and positive stages in the baby's development when he is alive and kicking in utero, very much existing and far from a nonperson, with both parents enjoying the pregnancy and the planning. It seems extraordinary to replace the memories of these stages, during which parents and the developing if unseen baby have a relationship, with those of a dead, cold, still, and possibly deformed baby. Even the baby of an early miscarriage may live long enough to be thought of as a person; more so is a baby who may have had as long as 20 weeks' visible and palpable activity. Occasionally the parents know before delivery that the baby has an abnormality incompatible with life; however this may not destroy the relationship although it must colour it. It is hard to see what the parents gain by substituting happy memories with ones which are at best negative and at worst shocking. While a funeral for a baby who has lived postnatally is important, it may do little for the parents of a stillborn child. We appreciate that Dr Lewis is looking for ways of making mourning easier for parents, but there is no room for dogmatism. A flexible approach is needed by all members of staff with the senior ones seeing that the conspiracy of silence, which he rightly condemns, is replaced by talking freely both in hospital and later at home.

\section{JANe M. CURRIE AND Simon CURRIE, St James's University Hospital, Beckett Street, Leeds LS9 7TF}

\section{Dr Lewis comments:}

Drs Jane Currie and Simon Currie reasonably wonder why I make little of parents' experiences of their babies in utero. In consultations with parents we do get them to relive these experiences, but they alone are not enough to facilitate mourning. Although a mother may have generally good feelings about her fetus, her ideas about its identity are necessarily poorly defined. This leaves room for much to go wrong. For instance, if parents have little sense of the personality of their stillborn baby, then the often quick replacement pregnancy, which itself tends to inhibit mourning, can be experienced as a continuation of the previous pregnancy. Then the newborn baby tends to be confused with the stillborn baby. This child may have a muddled sense of identity, suffer from a replacement child syndrome (Poznanski, 1972), or may be a victim of child abuse (Lewis, 1979).

As to contact with the dead baby being negative and shocking, fantasies reported by parents who have not seen their stillborn child are worse than the reality. Parents who have seen their stillborn child, including malformed babies. find relief in doing so and some treasure the experience.

Unfortunately, the psychological experience of stillbirth makes 'talking freely' rather difficult. GPs have been shown to have a strong reluctance to know, notice, or remember anything about a patient who has had a stillbirth (Bourne, 1968). Because a stillbirth is a void, a nonevent, it is difficult to think about, and it cannot occupy a potential thinking space in our minds. It is as if our very painful but vague thoughts about stillbirth occupy a wasteland, a black hole in the mind. Thus stillbirth is an empty drama that takes place at the interface of life and death: there is no catharsis. The experience of having made a baby tends to be annihilated by the experience of stillbirth. We encourage this annihilation by failing to acknowledge the stillbirth as having existed if we deny it a funeral.

The Curries, so keen to recognise the experience of the live fetus in utero as important, engage in doublethink when they feel a funeral for a stillbirth could 'do little' for the parents of the stillbirth. To the parents the baby does not cease to be important just because it hasn't breathed. Funerals are our society's way of marking the significance of death. A flexible approach sounds fine. Unfortunately, for the parents of a stillborn child, it often stands for unthinking inactivity, avoidance, and silence.

\section{References}

Bourne, S. (1968). The psychological effects of stillbirths on women and their doctors. Journal of the Royal College of General Practitioners, 16, 103-112.

Lewis, E. (1979). Two hidden predisposing factors in child abuse. Journal of Child Abuse and Neglect, 3, 327-330.

Poznanski, E. O. (1972). The 'replacement child': a saga of unresolved parental grief. Journal of Pediatrics, 81, $1190-1193$.

EMANUEL LEWIS

The Tavistock Clinic, Adult Department,

120 Belsize Lane,

London NW3 $5 B A$

\section{Congenital absence of the sternum}

Sir,

In the last few months we have seen 2 cases of congenital absence of the sternum in the newborn (as opposed to failure of fusion). There was no evidence of ectopia cordis nor was there any other congenital abnormality. A 
very detailed search for an aetiology was made but no cause could be found except for the fact that both the infants were born to mothers who came from south eastern Saudi Arabia where the diet is very deficient in vitamins, and both mothers had clinical evidence of panhypovitaminosis.

We think that this congenital abnormality in the infants may be due to chronic maternal riboflavine deficiency, as reported by Warkany and Nelson (1941) in experimental animals. Could I, through your columns, ask other paediatricians if they have come across this abnormality, and, if so, what was its aetiology?

\section{References}

Warkany, J., and Nelson, R. C. (1941). Skeletal abnormalities in offspring of rats reared on deficient diets. Anatomical Record, 79, 83-93.

Khalid N. Haque Faculty of Medicine, University of Riyad, PO Box 2925, Riyad, Saudi Arabia

\section{Acute inflammatory bowel disease in childhood: a new disease?}

Sir,

We should like to report on the subsequent progress of the child described as Case 1 in the paper by Manuel $e t$ al. (Archives, 1978, 53, 642).

This 6-year-old boy made a complete recovery after his initial illness and remained well for the next $2 \frac{1}{2}$ years. He then had an acute episode of diarrhoea and vomiting requiring no specific treatment, but the anorexia and diarrhoea persisted for 2 weeks. Six weeks later he became constipated. This did not respond to treatment with laxatives nor did it respond to repeated enemata over the next 4 months. He also began to have abdominal pains, which were thought to be due to his severe constipation, and he developed painful anal fissures.

Physical examination at this time showed no abnormality apart from a rather scarred anus with two fissures, but colonoscopy revealed scattered aphthoid ulcers throughout the colon characteristic of Crohn's disease, and an ulcerated terminal ileum.

The typical noncaseating granulomata, found in Crohn's disease, were present in the biopsies from the terminal ileum, confirming this diagnosis. He was started on sulphasalazine. He responded satisfactorily, with return of his stools to normal, disappearance of his abdominal pain, and healing of the anal fissures. He has since remained well.

It is interesting to speculate what relationship the initial illness reported in the Archives may have had to the subsequent one. Was this an acute presentation of Crohn's disease? This was considered at that time as it is rare to have a diarrhoeal illness of such severity in a child 6 years of age in this country. However at that time none of the usual diagnostic features of Crohn's disease was presentnamely the barium follow-through examination did not suggest Crohn's disease, and the abnormality on small intestinal biospy was severe but nonspecific, with an acute inflammatory cell reaction. Was the initial illness in fact a severe attack of acute gastroenteritis which, in some way, has precipitated the development of Crohn's disease in a susceptible individual? The answer to these questions is uncertain, and it remains quite possible that the two illnesses were unrelated. Nevertheless this case illustrates that although spontaneous resolutions can occur in acute inflammatory bowel disease for which no cause has been found, the eventual diagnosis of chronic inflammatory bowel disease is not thereby excluded, and long-term follow-up is necessary in children in whom this diagnosis is made.

C. A. Campbell, P. D. Manuel,
AND J. A. WAlkER-SMITH
Queen Elizabeth Hospital for Children,
Hackney Road,
London E2 $8 P S$

